\title{
The Semiotic Significance of China Rich List in Transitional China-Based on Forbes Rich List and Hurun Rich List
}

\author{
Wen-Hua CHEN ${ }^{1, a,{ }^{*}}$, Li-Li CHEN ${ }^{2, b}$ \\ ${ }^{1}$ Business School of Jiangxi Normal University, Nanchang, China \\ ${ }^{2}$ Business School of Jiangxi Normal University, Nanchang, China \\ ac13607085797@139.com, ${ }^{\mathrm{b}} 1228404735 @ q q . c o m$ \\ ${ }^{*}$ Corresponding author
}

Keywords: China rich list, Semiotics, Transitional economy, Entrepreneurship.

\begin{abstract}
Private enterprises are an important part of socialist market economy, playing a significant role in pushing economic development and social transition. Forbes China Rich List and Hurun Rich List are the miniature of Chinese economic and social development after reform-opening. Based on the study of semiotics, this thesis reveals the economic, industrial and cultural significance of China Rich List from three aspects through researching the information of China Rich List. The first one is the positive correlation of reform-opening, the rise of the rich class and Chinese economic growth. The second is the interaction of industrial upgrading, replacement of rich list and entrepreneurship. The third is interdependence of regional development, the rich gathering and entrepreneurship environment.
\end{abstract}

\section{Introduction}

The economic reform of 1978 opened the new era of Chinese rapid economic and social transformation. As the market economy emerging from China, a traditional agricultural country in which the planned economy taking the main role, as the microscopic subject, private enterprises increase their amount and enhance their strength gradually. According to Xinhua News Agency reported that by the end of 2013, in China, the amount of registered private enterprises has reached 1253.9 million; the amount of registered capital has arrived 39.3 billion dollars; the number of individual businesses has amounted 4439.3 million; the sum of people who work in the individual and private business has 219 million; the GDP contributed by private enterprises has amounted to more than 60 percent and the employment rate contributed by which also has reached to more than 80 percent. As an outstanding representative of different stages in private economy, the rich class is both a sign of the rise of China and a sign of Chinese entrepreneur class growing and expanding in a competitive market. And more and more people are paying attention to the rich, Forbes Rich List and Hurun Rich List appeared in the background of China's rise.

\section{Semiotics and rich list}

What is the sign? In brief, sign is a carrier for information and a medium for information transmission. Sign covers a wild field, anything meaningful people acknowledged can be regarded as a sign. Researchers who currently study semiotics consider sign as "a meaningful medium" which conveys information under certain conditions. Semiotics as the name suggests, is a subject focusing on signs. As a method for representing things, signs are used in every aspect of life. Nowadays, semiotics covers each subject at an enormous rate, including literature, music, law, folk custom, art and design and clothes etc. The significance behind the new "sign" - "Rich List" is mentioned and focused on constantly, but there are still not many systematic researches. Based on the theory of semiotics, this thesis tries to reveal the significance of the new sign-"Rich List" in transitional country China from economic, industrial and cultural aspects.

The number and structure of the rich are highly correlated with the process of country's opening, competitive advantage and industrial structure. According to "World Population Survey 
billionaires" which is issued by Wealth-X, a professional investigative agency and Swiss Bank Corporation in November 2013, the total net value of global billionaires' assets rose from 31 billion dollars in 2009 to 65 billion in 2013. And the number of billionaires increased 60 percent compared with that of 2009. Among them, The United States was ranked in the first place globally with 515 billionaires, while China was ranked in the second place with 157 billionaires. According to Forbes magazine, the number of Chinese billionaires has increased unprecedentedly by jumps in the world. The rich list changes every year, which reflects the changes of industrial pattern and ups and downs of individuals and represents the miniature of the world economic development.

In 1917, Forbes Rich List begins to pay attention to Chinese entrepreneurs and business leaders in 2003. The Hurun Rich List, it is for a young British's research and focus on china, which has traced and recorded the change of Chinese entrepreneur groups and has introduced constantly Chinese entrepreneurs to the world from 1999. Forbes Rich List and Hurun Rich List both have huge impact in China and catch the attention of the whole world. The change of the rich list is the barometer of Chinese private economic development. The rich list is a sign of fortune. Rich lists' changing means the industry and wealthy rising and declining. In the reform-opening era of competitive billionaires surging and in the background of changeable economy, what kind of change and enlightenment did the surge of Chinese rich and the change of China Rich List bring? The semiotic significance of China Rich List is a problem worthy of study in the process in which traditional society transforms into modern society.

\section{Reform-Opening, the rise of the rich class and the Chinese economic growth}

The increase of the amount of Chinese rich and the total value of their assets reveals that: if Deng Xiaoping hadn't opened China's reform-opening and China hadn't chosen the path of developing market economy, the rich class wouldn't have appeared, and the innovation, entrepreneurship and the overall rise in the Chinese rich class, which promoted the rapid growth of Chinese economy.

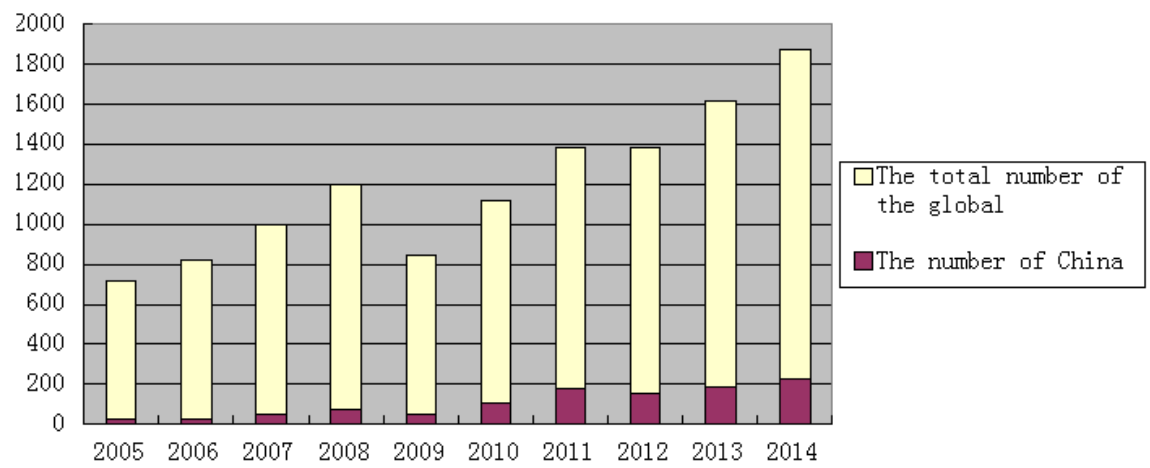

Figure 1 The number of Chinese rich growth in Forbes Rich List in 2005 to 2014

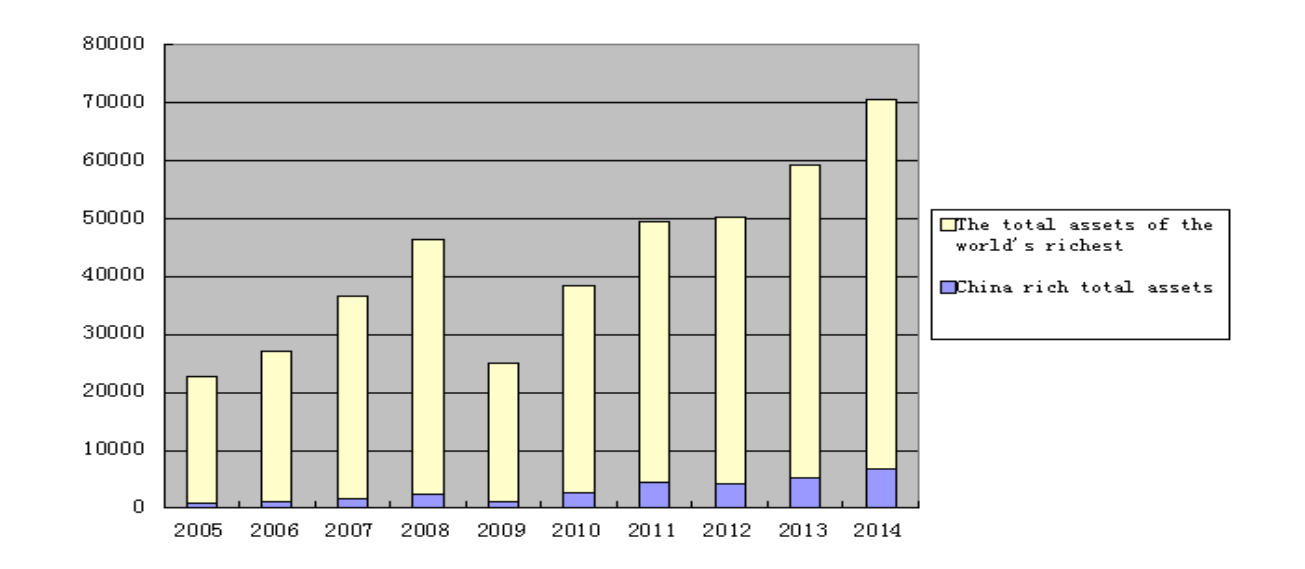

Figure 2 The total assets of Chinese rich growth in Forbes Rich List in 2005 to 2014 


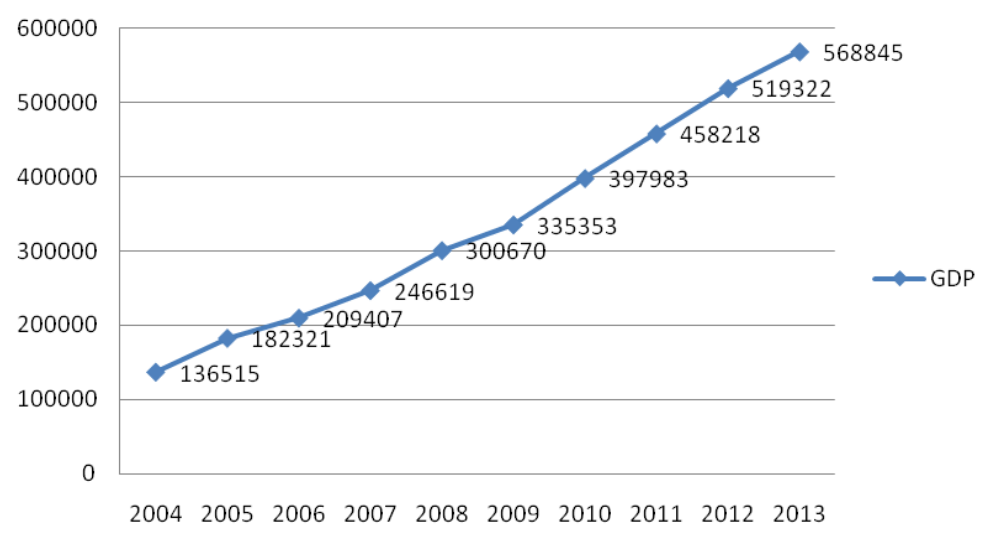

Figure 3 The growth condition of China's GDP

It can be seen from above that from 2005 to 2014 (except for the affected by the financial crisis in 2008, the world including China had shrunk dramatically of the rich number and total assets), with China's accession to the WTO, the breadth and depth increased of reform-opening, the number of rich in Forbes Rich List of the Chinese mainland from 24 in 2005 to 152 in 2014. The overall trend showed a rapid rise. The number of Chinese rich only after the United States (492), which is the second largest "super-rich plate" in the world. The total assets of Chinese rich from $\$ 81.3$ billion in 2005 highly speed increased to $\$ 667.05$ billion in 2014.Related to this appearance, in this decade of reform-opening, China's GDP from 13.6515 trillion Yuan in 2004 to 56.8845 trillion Yuan in 2004.In China, which is represented by the super-rich entrepreneurs group is in the process of "creative destruction", the economy is growing fast, China's GDP is the second in the world. So there are even commented by western expert China leading Asian rich quantity beyond Europe, redrawing the map of the world's economic center.

\section{Industrial upgrading, the replacement of rich list and the creation entrepreneurial spirits}

The combination of market demand and entrepreneurial spirit, made wealthy dream of having "creative destruction" endowments entrepreneurs come true and the emergence of rich class .The challenge of industrial upgrading, the change of China Rich List, let the individuals and families of not meeting consumer demand, changes in the industrial environment and management conditions to exit from rich list. Making a evaluation on the changing process of rich list by relying on market forces, not only a "significant symbol" about a country or region of consumer demand upgrading and industrial structure optimization, but also a record which entrepreneurship constantly heritage and bright in the industry practice.

\section{The static comparison of the rich industrial distribution in China and America}
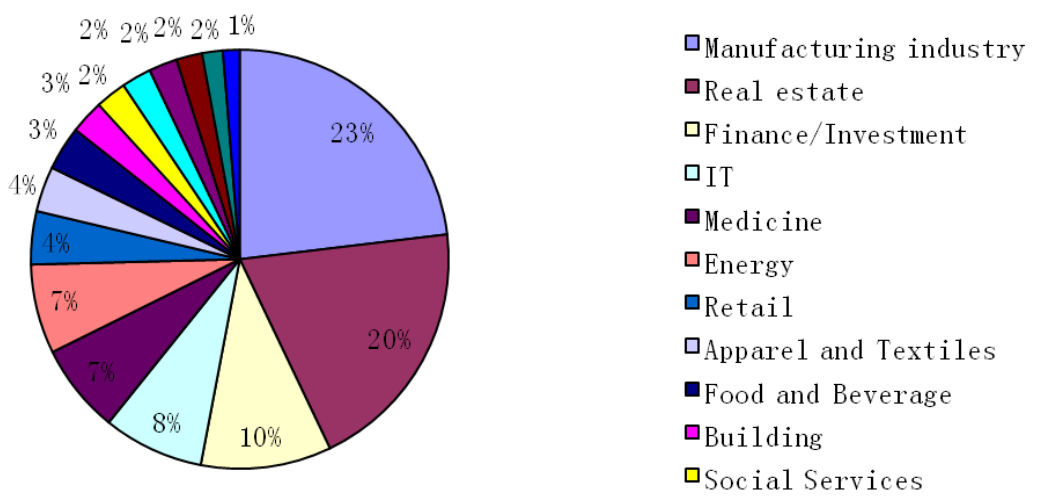

Figure 4 The industry distribution situation of Hurun China Rich List in 2014 


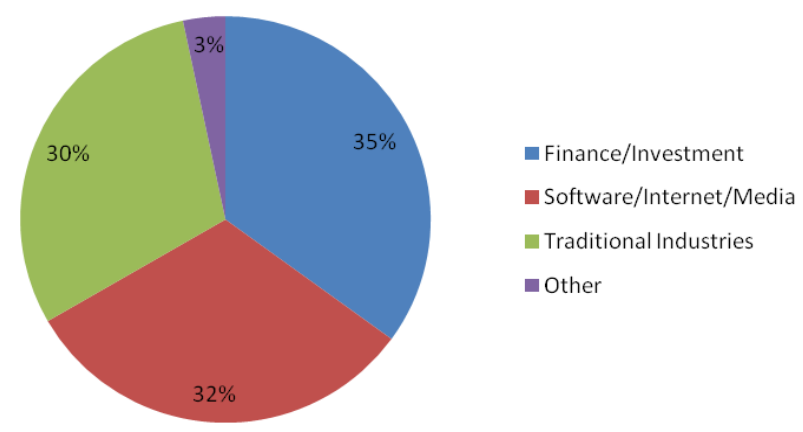

Figure 5 The US Rich List of industry distribution situation in 2014(Top 60)

Chart 5 shows that the proportion of the US financial/investment, services/retail and technology have been more than $60 \%$, and the traditional industries have been less than 35 percent; In chart 4 , Chinese traditional industry of real estate, manufacturing and energy is still as high as $49.8 \%$.The top ten of Hurun Rich List in 2014 is big shake-up, which can be seen as market signal for the direction of economic transformation. The new generation entrepreneurs of Chinese internet industry which guiding the consumer demand and applying the advantages of financial and science and technology, Huateng Ma, yanhong Li, Yun Ma fully entered into the top ten, ending the dominant position in the top ten of real estate, manufacturing, mining and other traditional industries which retained many years, confirming the industry trend of Finance/Investment, IT and the pharmaceutical industry in the US and other developed countries.

\section{The dynamic comparison of the rich industrial distribution in China and America}

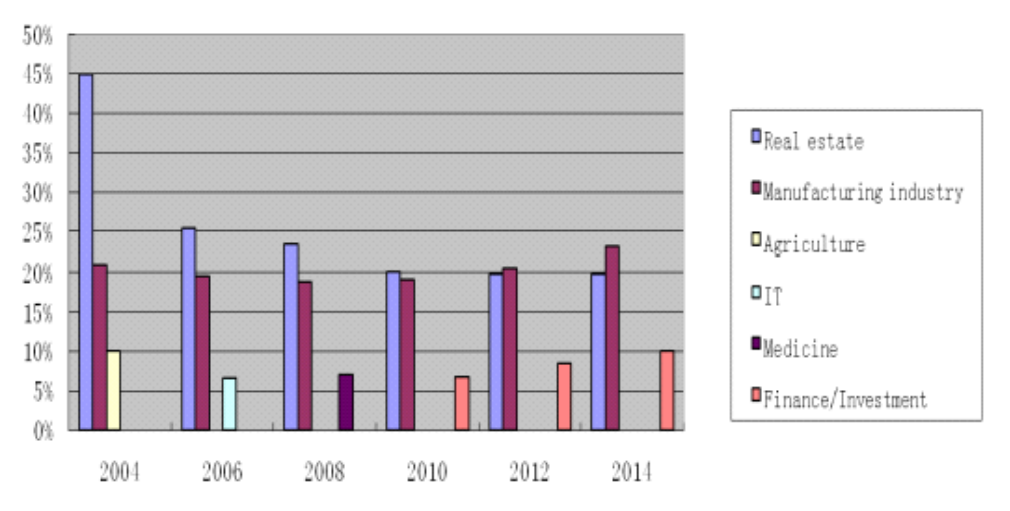

Figure 6 The number of leading industry distribution situation of the Hurun Rich List in 2004 to 2014

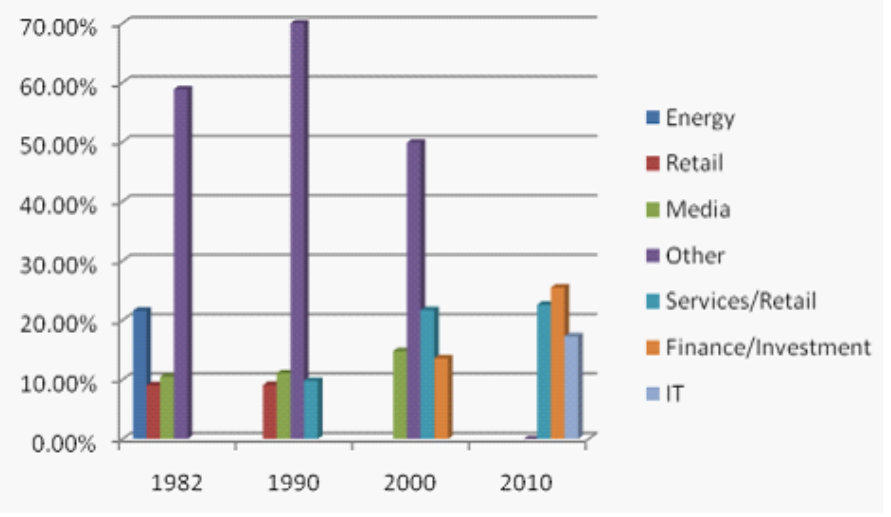

Figure 7 Leading industry distribution situation of the US Rich List in 1982 to 2014(Top 400) 
From the dynamic point of view, from 1982 to 2010, 29 years, the proportion of America's traditional industry such as energy, real estate is falling sharply, out of the top three ranks; But finance and investment industry has dominated, science and technology industry also rapidly arise, entering into the top three positions. For China, in this decade years, the real estate, manufacturing and other traditional industries continued to hold a dominant position. On the whole, the proportion of the number of rich tends to decline in traditional industries. Beginning in 2012, real estate magnate gave way for the manufacturing, the proportion dropped to the second, and the manufacturing rose to the leading position. As the representative of emerging industry, the rich proportion of the finance and investment, pharmaceuticals and IT is rapid upward trend. Before 2006, the proportion of these emerging industry average of less than 5\%. In 2014, finance and investment's proportion has risen to $10.1 \%$, becoming one of the leading industries. IT industry has also amounted to $7.8 \%$.

\section{The regional development, the rich gathering and entrepreneurship environment}

Motivation of regional development comes from innovation and entrepreneurship of entrepreneur groups, what place appropriate for entrepreneur's business and gathering is correlated with the degree of market opening in this area, the heterogeneity of human capital, traditional culture, entrepreneurship education, government service and other business environment. The geographical distribution and change of Chinese rich, just confirms this hypothesis.

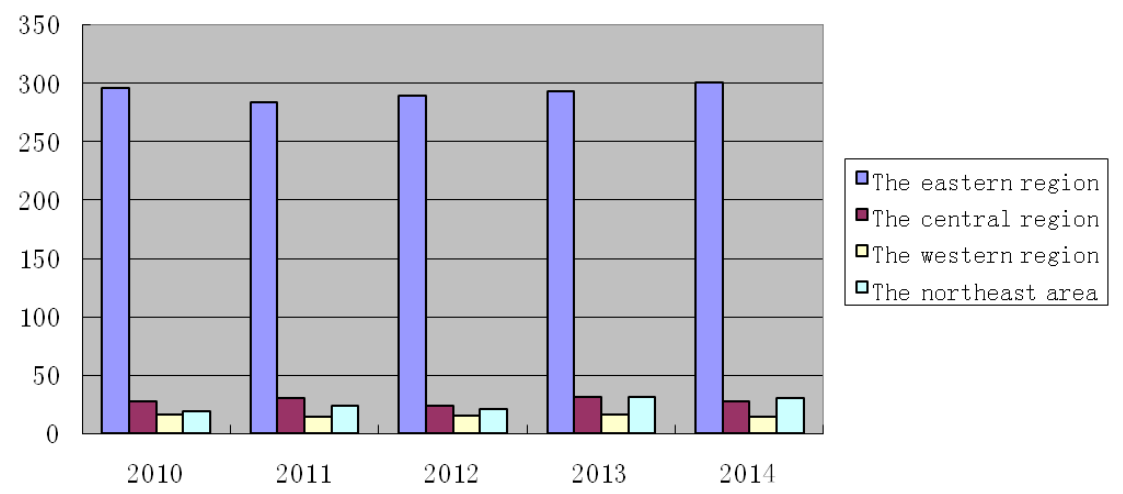

Figure 8 The geographical distribution of Forbes China Rich List from 2010 to 2014 (Top 400)

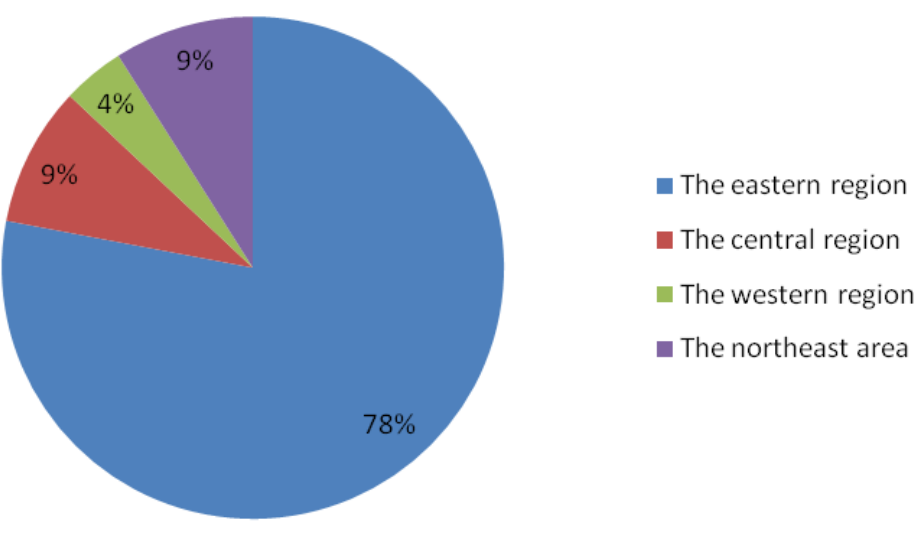

Figure 9 The geographical distribution ratios of Forbes China Rich List in 2014 (Top 400)

From figure 8 and figure 9, it can be seen that the geographical distribution in the coastal, the eastern region where earlier reform-opening and the earlier development of private economy and with the international standards, outshine others in 2010-2014 rich list. The average annual number of listed 78\% (Guangdong, Zhejiang, Jiangsu, Shanghai and Guangdong are distributed more 
wealthy areas).And relatively remote, closed and backward central and western regions and the northern region which had better industrial base at the planned economy period, where have small number of the rich, and western accounting for $4 \%$, central and northern accounting for $9 \%$ each.

\section{Conclusions}

China as a post-prone areas, the reform-opening began in 1978, accession to the WTO and other market-oriented choice, which provides the system precondition and guarantee for the rise of Chinese rich group. China's experience shows that the market mechanisms promoted gradually, after the reform-opening discovered and cultivated the entrepreneurship, and let the rich group as a whole emerged as possible and trends. In the process of free competition caused by industrial upgrading, entrepreneurship spawned the survival of the fittest of the rich and the constant turnover of rich list. This phenomenon reflected the trend of gradually optimize industrial structure. A country or region should create an open market conditions and provide effective government public services to attract and encourage entrepreneurial innovation activities. Only when entrepreneur groups rise sharply, it will gradually improve the national or local competitiveness through entrepreneurship accumulation and demonstration effect. Abandon the basic role of allocating resources in a market economy, which will stop with the "creative destruction" of the innovation and entrepreneurial spirit and activities of entrepreneurial groups, national or regional economic growth and social development will lack motivation.

\section{References}

[1] Allen.M.P.1987.The founding fortunes: a new anatomy of the super-rich families in America: Truman Talley Books.

[2] Goodman, D.2008.The New Rich in China: Future rulers,Present lives. London: Routledge.

[3] Lianglin Zhang. Peirce's Semiotics Review [J]. Yangzhou University Humanities and Social Sciences.1999 (1).

[4] Drucker. Innovation and Entrepreneurship [M] Hainan: Hainan Publishing House.2000.

[5] Weiping Wang. Significance of symbols from Peirce's semiotics [J]. Foreign Languages Teaching.2007. (7).

[6] LuPeng Compare Russia and Hungary's richest where from the richest. [N]. Weekend .2009.

[7] Dingren Zhong, genjing Sun. New era of transformation and development of the private economy [J].Economic Theory and Business Management.2011 (12):93-100.

[8] Yifu Lin. New structural economics [M] Beijing: Peking University Press, 2014. 